\title{
Comparação de parâmetros bióticos e abióticos entre fragmento de floresta secundária nativa e um reflorestamento de Pinus taeda $\mathrm{L}$.
}

\section{Comparison of biotic and abiotic parameters between a native secondary forest fragment and a Pinus taeda $\mathrm{L}$. reforestation}

\author{
Talita Parpinelli Ferracin ${ }^{1,3}$; Valéria Teodoro da Silva ${ }^{2,3}$; Paulo Souza Medri ${ }^{2,3}$; \\ Edmilson Bianchini ${ }^{2,3}$; Jose Antonio Pimenta ${ }^{2,3}$; Jose Marcelo Domingues Torezan \\ $4,3 *$
}

\section{Resumo}

A substituição das florestas naturais por plantios florestais comerciais, pode ser tão prejudicial quanto a agricultura ou a ocupação urbana. Porém, estudos sobre regeneração natural nessas áreas, apresentam resultados no desenvolvimento de espécies nativas no sub-bosque, sugerindo um processo sucessional favorável à recuperação da biodiversidade e também uma alternativa para a restauração. Este estudo teve como objetivo comparar parâmetros bióticos e abióticos entre fragmento de floresta secundária nativa e reflorestamento com Pinus taeda. O trabalho foi realizado no Parque Ecológico da Klabin, Fazenda Monte Alegre, Telêmaco Borba, Paraná. Foram avaliados dados bióticos (altura total, diâmetro à altura do peito (DAP - 1,30 m do solo) e área basal (AB), das espécies arbóreas com DAP $\geq 2,5 \mathrm{~cm}$ ) e dados abióticos ( $\mathrm{pH}$ e compactação do solo, cobertura de herbáceas, cobertura de dossel, espessura da serapilheira, temperatura e umidade relativa do ar). A maioria dos parâmetros diferiu entre o reflorestamento de pinus e a floresta secundária, como pH e compactação do solo, cobertura do dossel, presença de herbáceas e também a estrutura de tamanho da vegetação (diâmetro e altura). Observouse também, uma baixa regeneração no reflorestamento, evidenciada pela diferença na área basal. No entanto, houve regeneração no reflorestamento de pinus, e isso sugere que, com o tempo, poderá haver um incremento na regeneração da vegetação nativa, aumentando a riqueza de espécies e a complexidade estrutural da vegetação.

Palavras-chave: Estrutura florestal. Parâmetros bióticos e abióticos. Reflorestamento de Pinus taeda. Regeneração do sub-bosque.

\footnotetext{
Abstract

The substitution of natural forests for commercial forest plantations can be as damaging as farming or urban occupation. However, studies on natural regeneration in these areas show results in the development of native species in the understory, suggesting a successional process in favor of restoring biodiversity as well as an alternative forrestoration. This work aimed at comparing biotic and abiotic parameters between native secondary forest fragments and Pinus taeda reforestation. The study sites are located at Klabin Ecological Park, Monte Alegre Farm, Telêmaco Borba, Paraná. The following biotic data were evaluated: total height, diameter at breast height (DBH $-1.30 \mathrm{~m}$ above the ground) and basal

1 Mestranda do curso de Pós-graduação em Ciências Biológicas - Laboratório de Biodiversidade e Restauração de Ecossistemas - Departamento de Biologia Animal e Vegetal - Centro de Ciências Biológicas - Universidade Estadual de Londrina. E-mail: talitaferracin@yahoo.com.br

2 Laboratório de Ecologia Vegetal Departamento de Biologia Animal e Vegetal - Centro de Ciências Biológicas - Universidade Estadual de Londrina.

3 Programa de Pós Graduação em Ciências Biológicas - Universidade Estadual de Londrina.

4 Laboratório de Biodiversidade e Restauração de Ecossistemas - Centro de Ciências Biológicas - Universidade Estadual de Londrina. E-mail: torezan@uel.br

* Autor para Correspondência.
} 
area (BA), in tree species with $\mathrm{DBH} \geq 2.5 \mathrm{~cm}$. The following abiotic data were also evaluated: $\mathrm{pH}$, soil compaction, herb cover, canopy cover, litter thickness, air temperature, and relative humidity. Most parameters differed between pine reforestation and secondary forest, such as $\mathrm{pH}$ and soil compaction, canopy cover, herb presence and the size structure of vegetation (diameter and height). It was also observed a low regeneration in reforestation, evidenced by the difference in the basal area. However, there was regeneration in pine reforestation, suggesting that, over time, there will be an increase in the regeneration of the native vegetation, increasing the wealth of species and the structural complexity of the vegetation.

Key-words: Forest structure. Biotic and abiotic parameters. Pinus taeda reforestation. Nderstory regeneration.

\section{Introdução}

A perda e a fragmentação das florestas naturais permanecem como uma das principais causas da perda de biodiversidade (MURCIA, 1995). A substituição das florestas naturais por plantios florestais comerciais pode ser tão prejudicial quanto a agricultura ou a ocupação urbana (NOSS; COOPERRIDER, 1994). Porém, independente da intensidade de manejo e do valor de conservação, provavelmente todos os tipos de florestas plantadas tem alto valor de conservação em relação à agricultura (BROCKERHOFF et al., 2008).

Segundo Brockerhoff et al. (2008), houve, durante muito tempo, uma concepção de que as plantações florestais eram "desertos ecológicos", e que não proporcionavam habitat adequado para os organismos. Entretanto, muitos estudos têm documentado que estas plantações podem fornecer habitat para muitas espécies florestais nativas, animais e fungos (PARROTTA; TURNBULL; JONES, 1997; CARNUS et al., 2006). Até mesmo espécies incomuns e ameaçadas já foram documentadas nesses plantios.

Desse modo, Néri et al. (2005) citam a importância dos estudos de regeneração natural em plantios com espécies exóticas, como uma etapa na recuperação da cobertura florestal. Hartley (2002) confirma que o uso de monoculturas florestais para o restabelecimento da riqueza de espécies em áreas degradadas pode se tornar uma alternativa para a restauração.

Diversos estudos acerca da regeneração natural em plantios comerciais apresentaram resultados significativos no desenvolvimento de espécies florestais nativas no sub-bosque, sugerindo um processo sucessional favorável à recuperação da biodiversidade (REZENDE et al., 1994; GELDENHUYS, 1997).

Powers, Haggar e Fisher (1997) indicaram a importância da taxa de crescimento e da arquitetura das espécies plantadas em determinar a colonização por outras espécies. Silva Júnior, Scarano e Souza (1995), estudando uma monocultura de Eucalyptus grandis W. Hill ex Maiden, concluíram que as árvores plantadas agiram como espécies pioneiras em situações naturais, permitindo a colonização por espécies nativas. Este papel facilitador das florestas plantadas é devido à sua influência em determinadas características, como o microclima do sub-bosque, a complexidade estrutural da vegetação e o desenvolvimento de serapilheira e camadas de húmus durante os anos iniciais do crescimento da plantação (CARNUS et al., 2006).

Néri et al. (2005) complementaram que o aumento da complexidade da estrutura da vegetação possibilita novas estratégias de exploração do ambiente, elevando também a diversidade da fauna.

Este estudo visa a identificar diferenças bióticas e abióticas entre um fragmento de floresta secundária e um reflorestamento com Pinus taeda, foram levantadas duas hipóteses:

- A estrutura de tamanho (diâmetro e altura) do fragmento de floresta secundária difere da estrutura de um reflorestamento de Pinus taeda;

- O microclima e as condições edáficas diferem entre esses dois ambientes citados anteriormente. 


\section{Material e Métodos}

Área de estudo

O trabalho foi realizado no Parque Ecológico, localizado na Fazenda Monte Alegre (24o12'S, $\left.50^{\circ} 33^{\prime} \mathrm{W}\right)$, de propriedade da Empresa Klabin S. A., localizada no município de Telêmaco Borba, região centro-leste do estado do Paraná (Figura 1). Na paisagem local, observam-se três tipos de formações vegetacionais: Floresta Estacional Semidecidual, Floresta Ombrófila Mista e pequenas manchas de Campos Naturais (AZEVEDO et al., 2008). De acordo com os mesmos autores, esta paisagem é formada por um mosaico desses tipos florestais juntamente com reflorestamentos comerciais de Pinus spp., Eucalyptus spp. e Araucaria angustifolia (Bertol.) O. Ktze.

O clima da região é considerado como uma transição entre os tipos climáticos $\mathrm{Cfa}$ e $\mathrm{Cfb}$ de
Köppen, que é subtropical úmido com verão moderadamente quente a muito quente e invernos úmidos e frios. A precipitação anual média é $1.700 \mathrm{~mm}$ e a temperatura anual média é $19,5^{\circ} \mathrm{C}$ (MENDONÇA; DANNI-OLIVEIRA, 2002).

A área caracterizada como fragmento florestal secundário apresenta poucos indivíduos centenários, já que esta foi alvo de extrativismo durante a colonização da região, e existem algumas clareiras com abundante presença de herbáceas. O reflorestamento de pinus estudado foi plantado manualmente em setembro de 1972. Algumas práticas de manejo foram realizadas: 1972 a 1975 limpeza com enxada e de 1980 até 1989, desbastes. Portanto, o talhão está a 19 anos sem grandes interferências antrópicas.

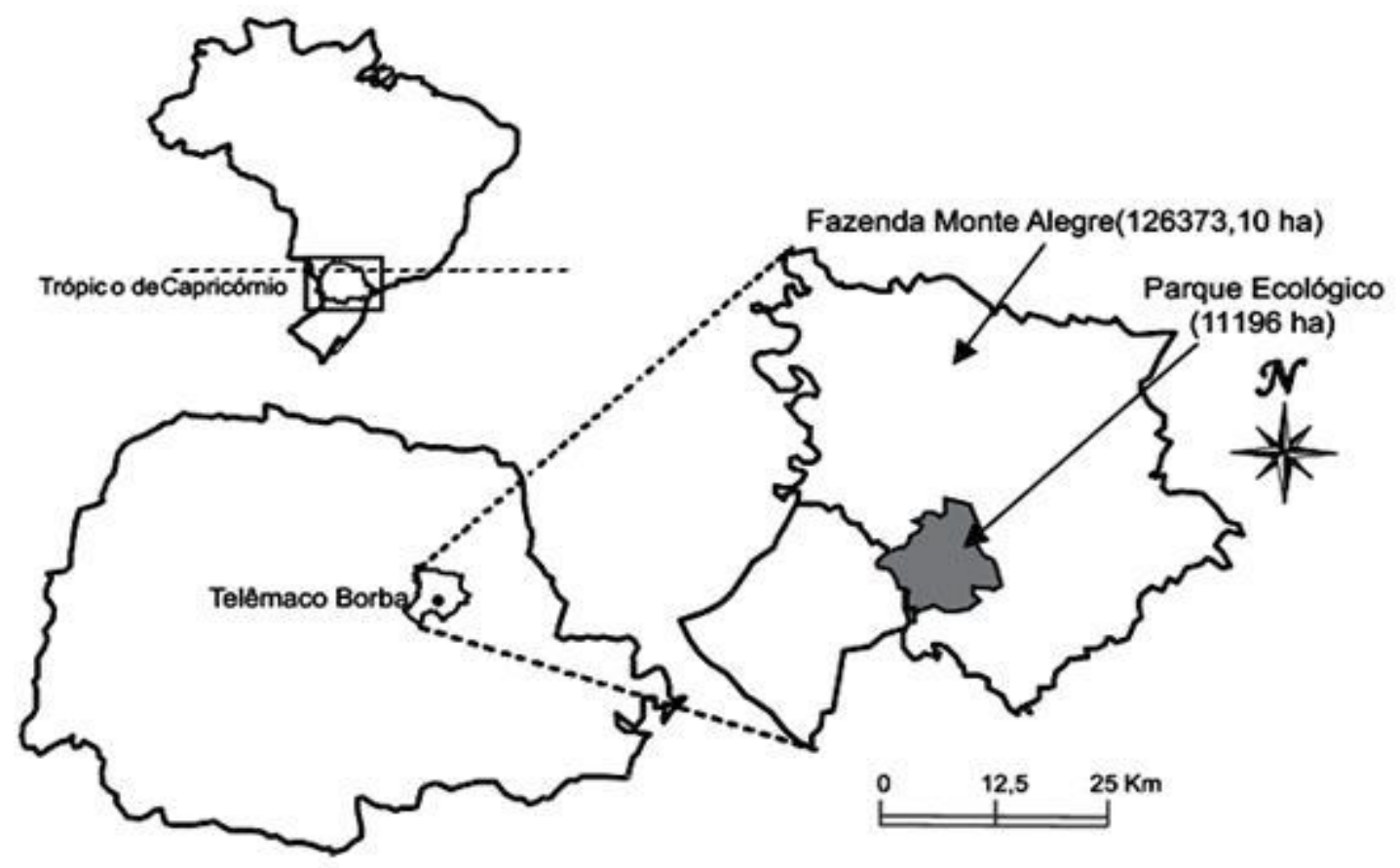

Figura 1. Localização da área de estudo (Parque Ecológico da Klabin, Fazenda Monte Alegre, Telêmaco Borba - PR). 


\section{Coleta de dados}

Foram montadas oito parcelas de $10 \mathrm{~m} \times 10 \mathrm{~m}$, perfazendo uma área total de $800 \mathrm{~m}^{2}$. Alocaramse quatro parcelas no reflorestamento de $P$. taeda e quatro na floresta secundária (FS). As parcelas foram alocadas em área de aparência homogênea dentro de cada ambiente. Em cada parcela foram coletados os seguintes dados:

- $\mathrm{pH}$ do solo: foram amostrados quatro pontos por parcela com um medidor portátil.

- Cobertura de herbáceas: as parcelas foram divididas em quatro quadrantes e em cada um deles, a cobertura de herbáceas foi estimada visualmente, em termos percentuais.

- Cobertura do dossel: foi determinada, em porcentagem, com um densiômetro esférico convexo. Realizaram-se quatro medidas, uma em cada vértice da parcela, de maneira que em cada medida o equipamento ficou voltado para o centro da parcela.

- Compactação do solo: foi estimada por meio da medida da força, em MPa, necessária à penetração de uma ponta de prova, com um penetrômetro portátil de solo. Foram quatro medidas por parcela, uma em cada quadrante.

- Espessura da serapilheira: as medidas foram feitas com fita métrica. O método consiste em cortar a serapilheira, em um único movimento, com uma ferramenta cortante que penetra no solo. Sem retirar a ferramenta, empurra-a para um dos lados e expõe o perfil aberto pelo corte. Esse método permite medir, em centímetros, a altura da necromassa. A espessura foi determinada em seis pontos regularmente distribuídos em cada parcela.

- Temperatura $\left({ }^{\circ} \mathrm{C}\right)$ e umidade relativa do ar $(\%)$ : foram registradas por coletores de dados eletrônicos automáticos (EL-USB-2,
$\mathrm{Rh}$ /Temp Data Logger, Lascar Eletronics), instalando-se três em cada área.

- Avaliação da regeneração florestal: foram amostrados todos os indivíduos com DAP (diâmetro a altura do peito - 1,30 $\mathrm{m}$ do solo) maior ou igual a $2,5 \mathrm{~cm}$. Desses indivíduos, foram medidos o diâmetro a $5 \mathrm{~cm}$ do solo (DAS) e o diâmetro a altura do peito (DAP). A altura dos indivíduos foi medida com uma fita métrica ou estimada visualmente com o auxílio de uma estrutura de altura conhecida. Nas comparações de área basal, foram realizadas duas análises diferenciadas. A primeira delas, considerando todos os indivíduos amostrados, com o intuito de verificar a contribuição dos mesmos na área basal total de cada local avaliado. A última, desconsiderando indivíduos com DAS acima de $36,7 \mathrm{~cm}$, em ambas as áreas (Floresta Secundária e Reflorestamento de Pinus taeda). Esse procedimento foi realizado para averiguar realmente a área basal dos indivíduos regenerantes, desconsiderando as árvores plantadas e aquelas de diâmetro equivalente na floresta secundária, para comparação.

Os dados foram analisados por meio de comparações entre médias e erro padrão de cada parâmetro avaliado. Para verificar se houve diferença na estrutura de tamanho entre as áreas, foi utilizado o teste de Kolmogorov-Smirnov (WERNECK et al., 2000).

\section{Resultados}

O reflorestamento de Pinus taeda apresentou maior cobertura de herbáceas, menor $\mathrm{pH}$ do solo, menor cobertura do dossel e menor compactação do solo, quando comparado à floresta secundária (FS) (Figura 2: A-D). Já, a espessura da serapilheira não diferiu entre as duas áreas (Figura 2: E). 

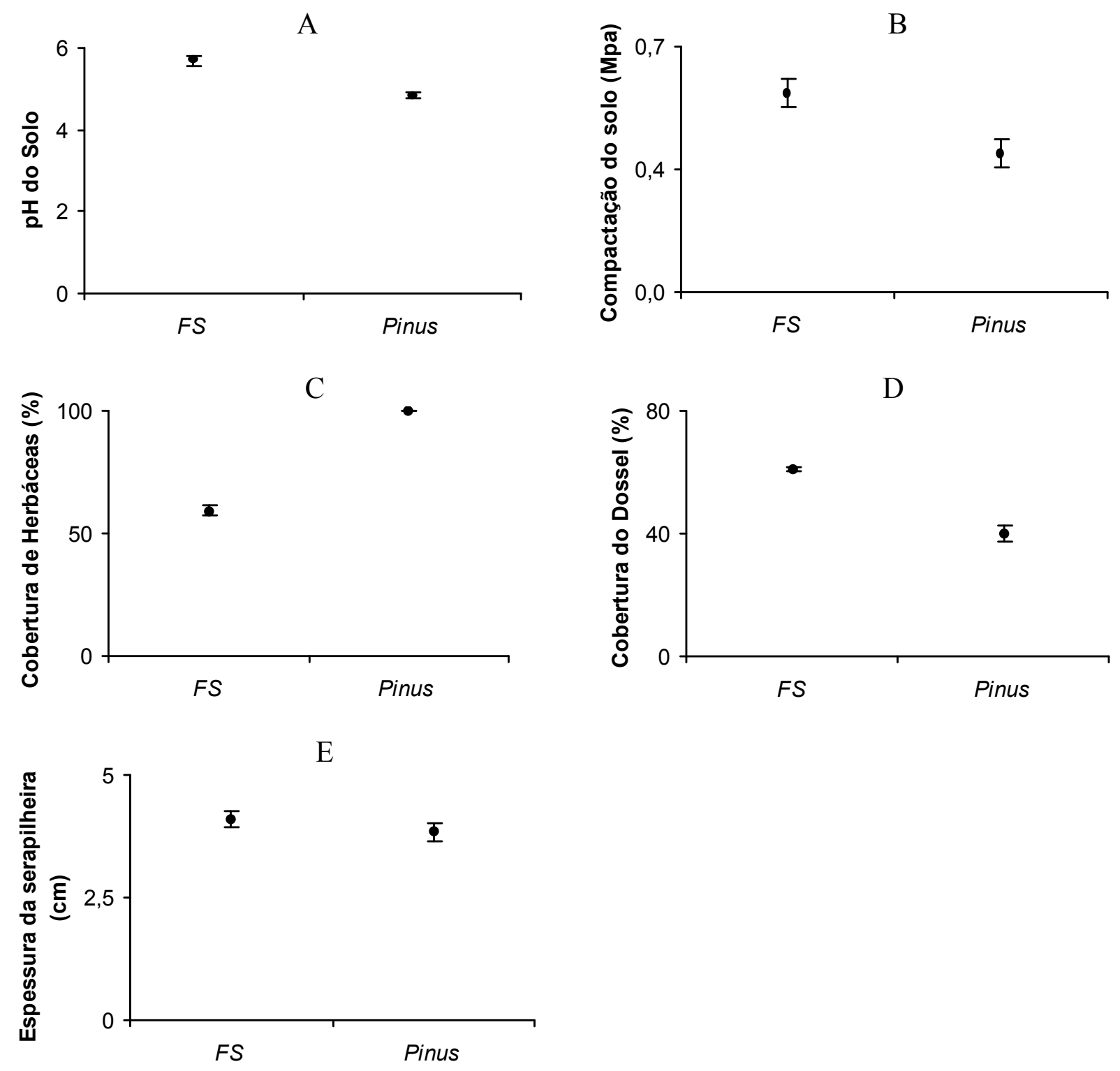

Figura 2. Comparação de parâmetros abióticos amostrados em fragmento de floresta secundária (FS) e em reflorestamento de Pinus taeda, Parque Ecológico, Telêmaco Borba, PR. pH do solo (A), compactação do solo (B), cobertura de herbáceas (C), cobertura do dossel (D) e espessura da serapilheira (E). Os pontos representam as médias e as barras verticais o erro-padrão.

As temperaturas mínimas e médias diárias foram maiores na floresta secundária, porém as máximas não diferiram entre as áreas (Figura 3).
A umidade relativa do ar noturna foi maior na floresta secundária, enquanto que a diurna foi maior no reflorestamento de Pinus taeda (Figura 4). 


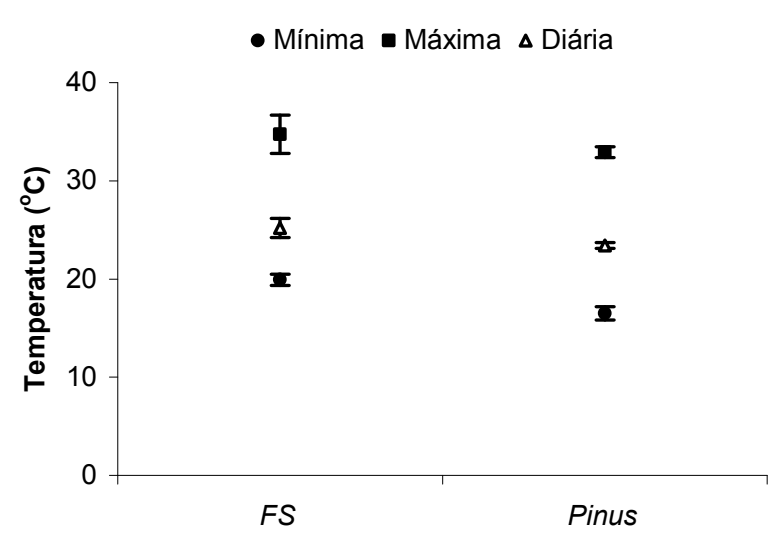

Figura 3. Médias das mínimas, máximas e médias diárias, amostradas em fragmento de floresta secundária (FS) e em reflorestamento de Pinus taeda, no Parque Ecológico, Telêmaco Borba, PR. Os pontos representam as médias e as barras verticais o erro-padrão.

O reflorestamento de Pinus taeda apresentou menor densidade de indivíduos por hectare que a FS (Figura 5). Em relação a área basal, não foi observada diferença significativa entre os dois locais (Figura 6A). Porém, ao se retirar os indivíduos de
- Umidade Noturna a Umidade Diurna

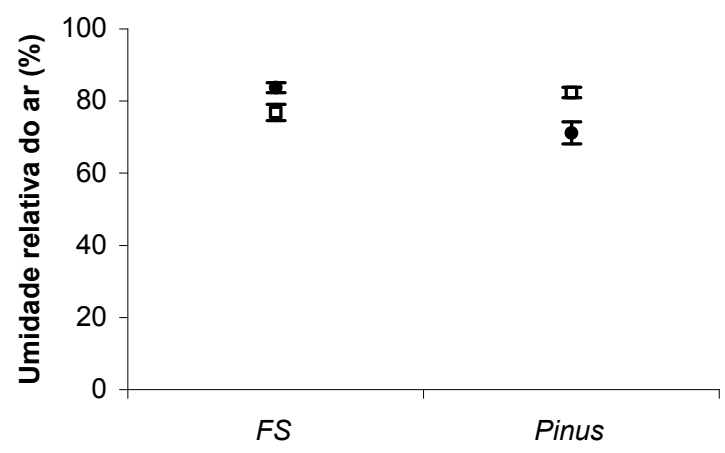

Figura 4. Média da umidade relativa do ar noturna e diurna amostradas em fragmento de floresta secundária (FS) e em reflorestamento de Pinus taeda, no Parque Ecológico, Telêmaco Borba, PR. Os pontos representam as médias e as barras verticais o erro-padrão.

Pinus taeda plantados e as árvores de diâmetro equivalente na FS, verificou-se que a área basal foi maior na FS (Figura 6B), e isso indica que os indivíduos plantados respondem por grande parte da biomassa nestes reflorestamentos comerciais.

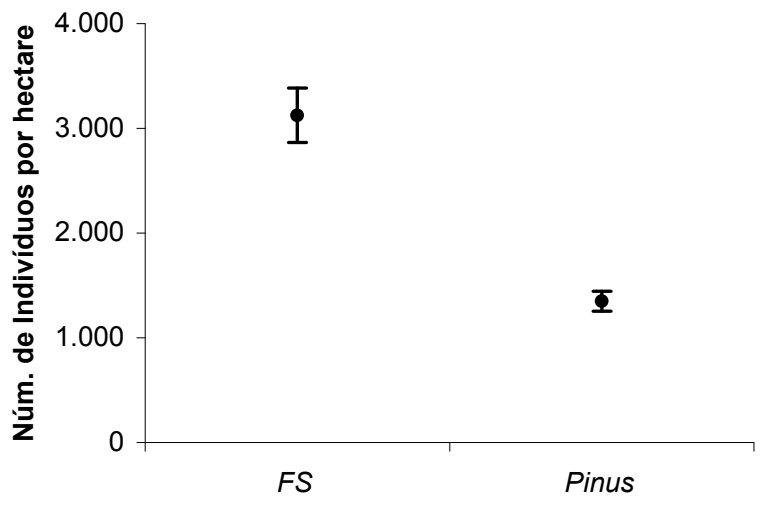

Figura 5. Número estimado de indivíduos por hectare em fragmento de floresta secundária (FS) e em reflorestamento de Pinus taeda, no Parque Ecológico, Telêmaco Borba, PR. Os pontos representam as médias e as barras verticais o erro-padrão. 
A

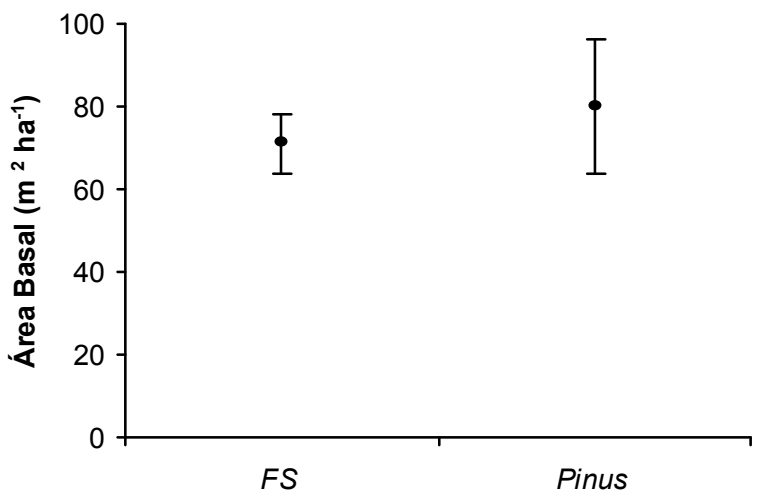

B

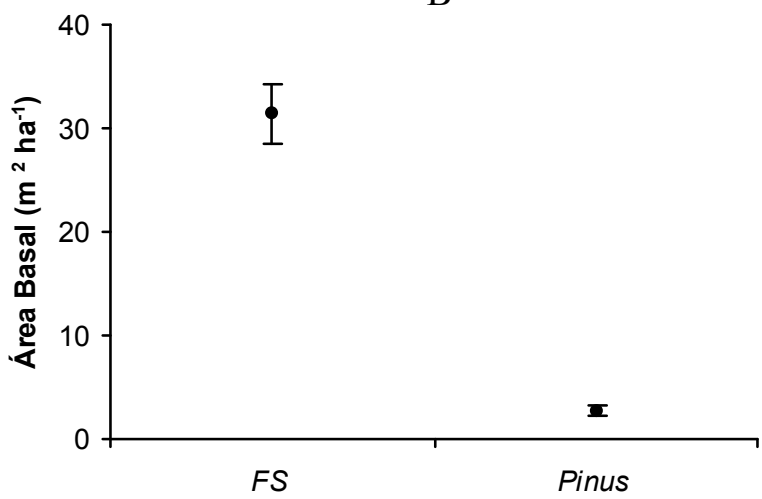

Figura 6. Áreas basais (m2.ha-1) amostradas em fragmento de floresta secundária (FS) e em reflorestamento de Pinus taeda, no Parque Ecológico, Telêmaco Borba, PR. A - todos os indivíduos amostrados; B - excluídos os indivíduos de Pinus taeda plantados e as árvores de diâmetro equivalente na floresta secundária. Os pontos representam as médias e as barras verticais o erro-padrão.

As análises de estrutura de tamanho da vegetação foram realizadas com todos os indivíduos amostrados, incluindo os pinus. As áreas diferiram entre si, em relação ao diâmetro e a altura (Figura 7). Na floresta secundária, em relação ao diâmetro, a primeira classe de tamanho apresentou o maior número de indivíduos com redução nas classes subseqüentes, caracterizando uma curva exponencial negativa (J invertido). A maior concentração de indivíduos nas primeiras classes de diâmetro pode caracterizar uma comunidade estoque, que é comum em florestas tropicais estáveis com idade e composição de espécies variadas. Na medida em que aumenta o tamanho da classe, a freqüência diminui até atingir seu menor índice na maior classe diamétrica, e isso caracteriza uma curva do tipo exponencial ou denominada "J" invertido (SCOLFORO; PULZ;
MELO, 1998).

O modelo de distribuição exponencial $\mathbf{J}$ invertido ou exponencial negativa sugere que as populações que compõem uma comunidade são estáveis e autoregenerativas, e existe um balanço entre mortalidade e recrutamento de indivíduos (PEREIRASILVA, 2004).

Já no reflorestamento, embora a primeira classe de tamanho apresente maior número de indivíduos, a curva exponencial não foi evidenciada.

Em relação a estrutura de altura, as áreas também diferiram significativamente entre si, pois se observou grande vazio de copas entre 12 e $27 \mathrm{~m}$ no reflorestamento.
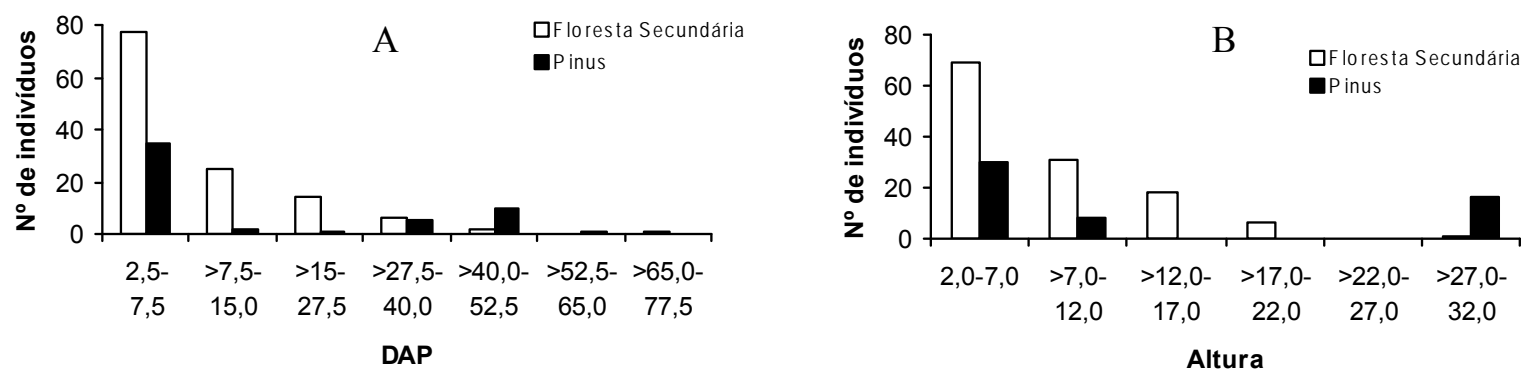

Figura 7. Número de indivíduos distribuídos entre classes de DAP (diâmetro a altura do peito) (A) e de altura total (B) em uma floresta secundária e um reflorestamento de Pinus taeda. Amostrados no Parque Ecológico, Telêmaco 


\section{Discussão}

Observou-se uma relação entre o menor índice de cobertura do dossel do reflorestamento de Pinus taeda e a elevada presença de herbáceas nesta área. Segundo Suganuma (2008), estudos indicam que a cobertura de herbáceas está diretamente relacionada com a luminosidade que penetra no sub-bosque e inversamente com cobertura de copa.

A menor densidade de indivíduos no reflorestamento de Pinus taeda pode ter sido decorrente de um dossel mais aberto, o qual dificulta o estabelecimento de plântulas de espécies características do interior da floresta, pois cria condições abióticas não-propícias à germinação e estabelecimento delas (TABARELLI; MANTOVANI, 1999).

A alta quantidade de herbáceas e as acículas de pinus também podem agir como uma barreira química e mecânica para a germinação de diversas espécies nativas, e, conseqüentemente, dificultara regeneração natural do sub-bosque. Vargas e Bernardi (2003) complementaram que este material forma uma camada protetora sobre o solo, e exerce efeito físico sobre as sementes e libera substâncias alelopáticas, influenciando consequentemente na regeneração natural.

Poggiani, Oliveira e Cunha (1996), afirmam que a decomposição da serapilheira de pinus pode, ao longo do tempo, modificar as características edáficas, de maneira que a decomposição destes resíduos provocaria uma diminuição no $\mathrm{pH}$. Dessa forma, possíveis alterações das condições normais do $\mathrm{pH}$ do solo, em plantios com Pinus spp., também pode contribuir com a menor densidade de regenerantes nestes locais.

Em relação ao microclima, Thébaud e Strasberg (1997) afirmaram que uma estrutura mais complexa dos fragmentos provavelmente está relacionada com uma menor variação de temperatura do que nos reflorestamentos e também pode funcionar como um tampão para a umidade relativa do ar, diminuindo a sua variação diária. Na FS, foi averiguada uma menor amplitude de variação na umidade relativa.

A diferença encontrada para a área basal indica que as árvores de pinus plantadas estão respondendo por grande parte da biomassa nesta área, ou seja, ainda são pouco expressivos, em termos de área basal, os indivíduos regenerantes.

Apesar da idade do reflorestamento, as estruturas de tamanho (diâmetro e altura) da vegetação foram diferentes entres as áreas de estudo. A análise dos dados indica que este tempo não foi suficiente para que a regeneração da vegetação nativa no subbosque do reflorestamento fosse similar àquela da floresta secundária.

\section{Conclusão}

A estrutura de tamanho da vegetação regenerante no sub-bosque do fragmento nativo é diferente em relação à encontrada no reflorestamento de Pinus taeda, do mesmo modo que algumas características abióticas diferiram entre os dois ambientes avaliados. Entretanto, como as condições abióticas no reflorestamento não foram extremas e foram observados regenerantes nativos no reflorestamento, sugere-se que, com a morte dos indivíduos de Pinus taeda, poderá ocorrer um incremento na regeneração da vegetação nativa, aumentando a riqueza de espécies e a complexidade estrutural da área, a longo prazo.

\section{Agradecimentos}

Os autores agradecem à empresa de papel e celulose Klabin S. A., pela hospedagem e suporte na realização do trabalho, ao professor Dr. José Lopes, pelo auxílio nas coletas e sugestões. À Universidade Estadual de Londrina pelo apoio de infra-estrutura laboratorial, e à CAPES pelo apoio financeiro ao programa de Pós-Graduação em Ciências Biológicas da UEL. 


\section{Referências}

AZEVEDO, T. I. N.; SEKIAMA, M. L.; VIEIRA, A. O. S.; BENNEMANN, S. T. Descrição física da micro bacia do Ribeirão Varanal e caracterização dos trechos. In: BENNEMANN, S. T.; VIEIRA, A. O. S.; SHIBATTA, O. A. (Org.). A flora e a fauna do Ribeirão Varanal: um estudo da biodiversidade no Paraná. Londrina: EDUEL, 2008. Cap. 1, p. 6-14.

BROCKERHOFF, E. G.; JACTEL, H.; PARROTTA, J. A.; QUINE, C. P.; SAYER, J. Plantation forests and biodiversity: oxymoron or opportunity? Biodiversity and Conservation, London, v. 17, p. 925-951, 2008.

CARNUS, J.; PARROTTA, J.; BROCKERHOFF, E.; ARBEZ, M.; JACTEL, H.; KREMER, A.; LAMB, D.; O'HARA, K.; WALTERS, B. Planted forests and biodiversity. Journal of Forestry, Washington, v. 104, n. 2, p. 65-77, 2006.

GELDENHUYS, C. J. Native forest regeneration in pine and eucalypt plantations in Northern Province, South África. Forest Ecology and Management, Amsterdam, v. 99, p. 101-115, 1997.

HARTLEY, M. J. Rationale and methods for conserving biodiversity in plantation forests. Forest Ecology and Management, Amsterdam, v. 155, p. 81-95, 2002.

MENDONÇA, F. A.; DANNI-OLIVEIRA, I. M. Dinâmica atmosférica e tipos climáticos predominantes da bacia do Rio Tibagi. In: MEDRI, M. E.; BIANCHINI, E.; SHIBATTA, O. A.; PIMENTA, J. A. (Ed.). A bacia do rio Tibagi. Londrina: EDUEL, 2002. Cap. 4, p. 63-66.

MURCIA, C. Edge effects in fragmented forests: implications for conservation. Trends in Ecology \& Evolution, Amsterdam, n. 10, p. 58-62, 1995.

NÉRI, A. V.; CAMPOS, E. P. T.; DUARTE, G.; MEIRA NETO, J. A. A.; SILVA, A. F.; VALENTEL, G. E. V. Regeneração de espécies nativas lenhosas sob plantio de Eucalyptus em área de cerrado na floresta nacional de Paraopeba, MG, Brasil. Acta Botânica Brasileira, São Paulo, v. 19, n. 2, p. 369-376, 2005.

NOSS, R. F.; COOPERRIDER, A Y. Saving Nature's Legacy: protecting and restoring Biodiversity. Washington: Island Press, 1994.

PARROTTA, J. A.; TURNBULL, J.; JONES, N. Catalyzing native forest regeneration on degraded tropical lands. Forest Ecology and Management, Amsterdam, v. 99, p. 1-8, 1997.

PEREIRA-SILVA, E. F. L. Alterações temporais na distribuição dos diâmetros de espécies arbóreas. 2004. Monografia (Pós-graduação em Biologia Vegetal) Universidade Estadual de Campinas, Campinas.
POGGIANI, F.; OliveIRA, R. E.; CUNHA, G. C. Práticas de ecologia florestal. Documentos Florestais, Piracicaba, n. 16, p. 1-44, 1996.

POWERS, J. S.; HAGGAR, J. P.; FISHER, R. F. The effect of overstory composition on understory woody regeneration and species richness in 7-year-old plantations in Costa Rica. Forest Ecology and Management, Amsterdam, v. 99, p. 43-54, 1997.

REZENDE, M. L.; VALE, A. B.; REIS, M. G. F.; SILVA, A. F.; NEVES, J. C. L. Regeneração natural de espécies florestais nativas em sub-bosque de Eucalyptus grandis e em mata secundária no Município de Viçosa, Zona da Mata, MG, Brasil. In: SIMPÓSIO SUL-AMERICANO E SIMPÓSIO NACIONAL DE RECUPERAÇÃO DE ÁREAS DEGRADADAS, 1 e 2., 1994, Foz do Iguaçu. Anais... Foz do Iguaçu, 1994. p. 409-418.

SCOLFORO, J. R. S.; PULZ, F. A.; MELO, J. M. Modelagem da produção, idade das florestas nativas, distribuição espacial das espécies e análise estrutural. In: SCOLFORO, J. R. S. (Coord.). Manejo florestal, Lavras: UFLA/FAEPE, 1998. p. 189-246.

SILVA JÚNIOR, M. C.; SCARANO, F. R.; SOUZA, F. C. Regeneration of an Atlantic forest formation in the understorey of a Eucalyptus grandis plantation in south eastern Brazil. Journal of Tropical Ecology, Cambridge, v. 11, p. 147-152, 1995.

SUGANUMA, M. S. Avaliação de sucesso da restauração florestal baseada em estrutura florestal e processos do ecossistema. 2008. Dissertação (Mestrado em Ciências Biológicas) - Universidade Estadual de Londrina, Londrina.

TABARELLI, M.; MANTOVANI, W. A regeneração de uma floresta tropical montana após corte e queima (São Paulo-Brasil). Revista Brasileira de Botânica, São Paulo, v. 22, p. 217-223, 1999.

THÉBAUD, C.; STRASBERG, D. Plant dispersal in fragmented landscapes: a field study of wood colonization in rainforest remnants of the Mascarene Archipelago. In: LAURANCE, W. F; JUNIOR. BIERREGAARD, R. O. (Ed.). Tropical forest remnants: ecology, management, and conservation of fragmented communities. Chicago: The University of Chicago Press, 1997. p. 321-332.

VARGAS, L.; BERNARDI, J. Manejo de plantas daninhas na produção orgânica de frutas. Vacaria: Embrapa Uva e Vinho, 2003. p. 1-11. (Circular Técnica, n. 45).

WERNECK, M. S.; PEDRALLI, G.; KOENIG, R.; GISEKE, L. F. Florística e estrutura de três trechos de uma floresta semidecídua na Estação Ecológica do Tripuí, Ouro Preto, MG. Revista Brasileira de Botânica, São Paulo, v. 23, n. 1, p. 97-106, 2000. 
Recebido em: 11 de agosto de 2008

Aceito em: 13 de agosto de 2010 